\title{
GUERREIRO RAMOS E A QUESTÃO RACIAL NO BRASIL
}

\author{
Ricardo Ramos Sbiota*
}

“O Brasil é o país mais racista do mundo" (Guerreiro Ramos, 1981)

RESUMO: No início de sua trajetória de pesquisas sobre o Brasil, Guerreiro Ramos reconhece a especificidade da questão racial. Desenvolve uma percepção e atividade crítica sobre ela no Brasil. Ao recusar as teorias raciais vigentes, pois estas, segundo ele, lidavam com pessoas, agentes sociais e não meros "objetos" do conhecimento, ele constrói uma visão emancipatória, voltada para a realização de uma democracia racial efetiva, autêntica e preocupada com a emancipação econômica nacional, quando ainda estava em disputa a internacionalização da economia brasileira nos anos 1950.

PALAVRAS-CHAVE: Questão racial. Preconceito de cor. Questão nacional. Pensamento social. Sociologia brasileira.

\begin{abstract}
Early in his researcher career in Brazil, Guerreiro Ramos acknowledges the specificity of the racial issue. Develop a perceptivity and critic activity about it in Brazil. By refusing the prevailing racial theories, because these, according to him, dealt with people, social agents and not mere "objects" of knowledge, he builds an emancipatory vision, toward the realization of an effective racial democracy, authentic and concerned with the national economic emancipation, when was yet in dispute the internationalization of the Brazilian economy in the 1950s.
\end{abstract}

KEYWORDS: Racial Issue. Color prejudice. National issue. Social thought. Brazilian sociology.

* Aluno do Programa de Pós-Graduação em Sociologia da Unicamp. Contato: rrshiota@gmail. com. Este artigo é uma versão reduzida do segundo capítulo de minha dissertação de mestrado, que teve apoio financeiro da FAPESP. 


\section{INTRODUÇÃO}

Guerreiro Ramos dedicou-se ao estudo da questão racial no Brasil entre a segunda metade da década de 1940 e o primeiro lustro da década de 1950 , período quando seus trabalhos relativos ao tema foram publicados. Ao longo de suas publicações, o autor desenvolve uma perspectiva peculiar sobre o assunto, que vai da negação ao reconhecimento da existência do "preconceito de cor"1. Desenvolve uma concepção particular e crítica do problema digna de ser rememorada.

O objetivo deste artigo é realizar um panorama da produção intelectual de Guerreiro Ramos, no que diz respeito à questão racial e à temática do negro no Brasil. Faço uma leitura interna dos textos do autor. Apresento as ideias dele em relação aos diálogos estabelecidos em seu tempo com outros intelectuais. Com o auxílio de intérpretes, pontuo algumas apropriações teóricas e críticas recebidas por Guerreiro Ramos. Também busco situá-lo em relação às instituições que participou, as quais, de algum modo, acabaram marcando o seu modo de pensar o Brasil.

\section{PRIMEIROS TRABALHOS}

Durante a segunda metade da década de $1940^{2}$, época em que participou do Departamento Nacional da Criança e, em seguida, do Departamento de Administração do Serviço Público (DASP), instituições criadas por Getúlio Vargas, a temática do negro no pensamento de

\footnotetext{
1 Segundo Guimarães (2004), o campo temático dos estudos das relações raciais no Brasil definido como "preconceito de cor" esteve em foco nos anos 1950 a 1970, caracterizando-se a partir de determinadas filiações teóricas, como a influência da Escola de Chicago e seus representantes que vieram pesquisar e lecionar no Brasil; bem como da chamada "Escola paulista de sociologia" e teóricos nacionalistas, evidenciando ainda um determinado modo de enfocar o problema. Depois de 1970, porém, esse campo temático foi substituído pelo conceito de "racismo". Ver: GUIMARÃES (2004).

${ }^{2}$ Mediante a dificuldade de acesso aos textos de Guerreiro Ramos sobre o tema, publicados principalmente em jornais, tomo como referência os estudos de Maio (1997), Guimarães \& Macedo (2008), que reproduzem e comentam esses textos.
} 
Guerreiro "não se afastava muito do mainstream das ciências sociais da época” (GUIMARÃES; MACEDO, 2008, p. 152). Ressoavam nas questões postas pelo autor a insustentabilidade do racismo, mediante as descobertas das ciências sociais norte-americanas, como o culturalismo de Franz Boas e os trabalhos da Escola de Chicago, representados por Robert Park (MAIO, 1997).

Apesar disso, o "racismo" é visto por Guerreiro Ramos como remanescente e difuso no senso comum, uma ideologia que consagra a dominação política e social das elites brancas. Tratar-se-ia, conforme convencionado no debate da época, de um preconceito à brasileira: sutil e vinculado à questão de classe. "Entre nós, o preconceito racial perde em importância para os outros dois aspectos da questão: o preconceito de classe e a incompatibilidade de dois mundos mentais distintos" (RAMOS apud GUIMARÃES; MACEDO, 2008, p. 152). Tal como Donald Pierson ${ }^{3}$ havia argumentado, tendo como referência o caso norte-americano, o racismo brasileiro deriva das péssimas oportunidades culturais e econômicas que os negros tinham acesso. Ademais, Guerreiro Ramos admitia uma situação cultural pós-escravidão incompatível e irredutível à cultura branca dominante no Brasil e recomendava a ascensão econômica e cultural do negro, o que implicava a reafirmação do branqueamento. Como dizia Guerreiro Ramos naqueles idos da década de 1940:

[...] Grande número de negros brasileiros ainda não se incorporou à cultura dominante no Brasil, que é a européia de base latina. Existe uma cultura negra no Brasil com seu sincretismo religioso, seus hábitos alimentares, sua medicina de "folk", sua arte, sua moral, etc. O mundo mental destes grupos é incompatível com o das classes dominantes. O negro brasileiro pode "branquear-se", na medida em que se eleva economicamente e adquire os estilos comportamentais

\footnotetext{
${ }^{3}$ Trata-se da tese de doutorado do autor, orientado por Robert Park, traduzida e publicada como: PIERSON, Donald. Brancos e Pretos na Babia: estudo de contato racial. São Paulo: Companhia Editora Nacional, 1945. No ano de 1942, Guerreiro Ramos participou de um curso sobre técnicas e métodos de pesquisa oferecido pelo DASP e ministrado por Donald Pierson. Para uma breve síntese sobre este autor ver: OLIVEIRA (1995).
} 
dos grupos dominantes. O "peneiramento" social do homem de cor brasileiro é realizado mais em termos de cultura e de "status" econômico, do que em termos de raça (RAMOS apud GUIMARÃES; MACEDO, 2008, p. 152-153).

Há como pressuposto nestas afirmações as teses evolucionistas sobre o pensamento primitivo de Edward Burnett Tylor e James George Frazer. Além, principalmente, das teses de Lucien Lévy-Bruhl, que fez a distinção entre lógica do sentimento e lógica da razão, como se o "pensamento primitivo" e suas representações "místicas" percebesse o mundo de modo pré-lógico, diferente dos civilizados. Nesta apropriação do pensamento eurocêntrico, o "despreparo" dos negros tinha suas origens no âmbito educacional e cultural, embora se pressupusesse também uma "deficiência" de mentalidade, estigma da raça e de raízes africanas (MAUÊS, 1989).

Em decorrência desta visão, no princípio de seus estudos sobre o negro, Guerreiro Ramos desaconselhava qualquer tipo de organização política voltada contra o preconceito de cor, pois, para ele, a melhoria das condições de vida do negro, por si mesma, acabaria com o preconceito sofrido (MAIO, 1997). A partir do diagnóstico da questão racial como um problema de origem econômica, cultural e educacional não propriamente racial, a luta dos negros devia se voltar contra a desigualdade existente em relação aos brancos. "Os meios de luta do negro brasileiro não devem ser demagógicos nem sentimentais, têm que ser adequados ao modo como se coloca o problema no Brasil. Penso que os homens de cor não devem jamais organizar-se para combater o preconceito racial". Ante o preconceito, o negro devia se portar com atitude de "indiferença e até humorística, nunca de indignação” (RAMOS apud GUIMARÃES; MACEDO, 2008, p. 154).

Abdias Nascimento, militante e fundador do Teatro Experimental do Negro (TEN 1944-1968), amigo de Guerreiro Ramos desde 1939, diverge em relação a essa concepção não diretiva do autor, vista por ele como "contemplativa" e "resignada": 
Durante quase todo o período de após abolição, o negro rezou por essa cartilha de assistir de braços cruzados e sorriso nos lábios, à sonegação dos seus direitos de cidadão. Sua decadência atual, em grande parte, pode ser levada à conta desse comportamento contemplativo e resignado. E isso é tão verdade quando se examina o combate ao racismo no Brasil[...]. É preciso viver no seio das organizações negras para se constatar que o seu espírito de luta não é demagógico nem puramente sentimental. O que há é o aproveitamento das lições sociológicas de Gilberto Freyre e Arthur Ramos, orientando suas atitudes em bases democráticas, sem sectarismos, e longe dos ódios que isolam e separam os homens. (NASCIMENTO apud GUIMARÃES; MACEDO, 2008, p. 154).

A participação de Guerreiro Ramos no TEN, ocorrida em 1948, demandou uma revisão de suas concepções sobre o tema e o reconhecimento da presença do preconceito de cor na sociedade brasileira, independentemente de outras variáveis consideradas.

Conforme Maio (1997) o artigo publicado no jornal A Manhã, intitulado Imigração e preconceito (04/07/1948), referente a uma pesquisa realizada no DASP pelo autor, com aplicação de questionários, constatou a presença de forte preconceito contra o negro e o mulato nos quadros burocráticos da administração da antiga Capital Federal. Os indícios de preconceito racial, agora confirmados pelo seu próprio trabalho de investigação, foram favoráveis à autocrítica do autor e à elaboração de um novo diagnóstico que facultasse alguma ação de sua parte.

Além disso, na publicação de Contatos raciais no Brasil, na primeira edição do veículo de comunicação Quilombo (1948), Guerreiro Ramos admite a presença do "preconceito de cor" e não do "preconceito de raça" na sociedade brasileira a qual não seria estratificada por divisão de casta. O preconceito de raça e a segregação que dele deriva, dizia respeito à realidade norte-americana e sul-africana, ao passo que, no Brasil a miscigenação obnubilava sua presença, sendo mais adequado o conceito de preconceito de cor. A questão do racial é matizada pelo autor, vista 
pela sua particularidade, conforme as diferenças marcantes no Brasil: em alusão às regiões do país, às diferenciações de classe social e entre o meio rural e o meio urbano.

A incompatibilidade do "mundo mental" dos negros com a cultura europeia latina dominante é mitigada. Apresenta-se nos termos de uma "psicologia diferencial do negro brasileiro", a qual segmenta os negros entre si, gerando tensões sociais em razão do corte classista existente no interior da população negra. Guerreiro Ramos inicia em 1948 suas críticas à perspectiva culturalista que valorizava as tradições africanas, vistas como "sobrevivências" e conferia um caráter estático ao negro no Brasil.

\section{O TEATRO EXPERIMENTAL DO NEGRO (TEN)}

Constatada a especificidade da questão racial e a existência do preconceito de cor no Brasil, era necessário lutar contra o mesmo. Em Contatos raciais no Brasil (1948), Guerreiro Ramos indica essa pretensão através da busca de uma "sociologia de caráter operativo, que auxiliasse o negro a encontrar sua própria identidade no contexto das mudanças ocorridas nos anos 1940 e 1950 no Brasil” (MAIO, 1997, p. 271). O reconhecimento do preconceito de cor, desse modo, motivou a adesão de Guerreiro Ramos a um convite feito por Abdias Nascimento:

Há cinco anos passados, o fundador do TEN me procurava para obter meu apoio à sua iniciativa e eu o despistei, como se despista a um demagogo e a um negro ladino. Ficou, entretanto, deste encontro a curiosidade pelo movimento. Acompanhei o TEN. Várias conversas, vários encontros com o fundador do TEN. E em certo momento vi, enxerguei a pista jamais suspeitada que ele estava abrindo a vida nacional $[\ldots]$.

A força daquela intuição venceu as minhas resistências e até mesmo o meu escrúpulo em confundir-me com certo tipo de reivindicador contumaz (RAMOS, 1950, p. 35-36). 
Em publicação recente na qual versa sobre o TEN, sob o olhar do presente, Abdias Nascimento (2004) apresenta o TEN como agente de ação social contra o racismo, lastreado num fórum de ideias e debates, cuja finalidade era a promoção de igualdade de direitos e oportunidades para os negros. "Propunha-se o TEN a trabalhar pela valorização social do negro no Brasil, através da educação, da cultura e da arte" (NASCIMENTO, 2004, p. 210).

Para ele, tratava-se de formar uma nova visão sobre o negro brasileiro, que rompesse com o estigma ainda vigente da escravidão nas manifestações culturais e populares, de modo que o esforço repercutisse nos formadores de opinião pública. Para isso, as ações do TEN dirigiam-se à valorização estética e à melhoria das condições de vida da população negra através de "ações em favor da coletividade afro-brasileira discriminada no mercado de trabalho, habitação, acesso à educação e saúde, remuneração, enfim, em todos os aspectos da vida na sociedade" (NASCIMENTO, 2004, p. 221).

Além das iniciativas cênicas, artísticas, de grupoterapia e da promoção de novos estudos, o TEN desenvolveu atividades políticas "pragmáticas" para influir junto aos formadores de opinião pública e autoridades - por meio de denúncias veiculadas pelo Quilombo -, e proposição de projetos. Guerreiro Ramos define esses objetivos como sendo:

1) formular categorias, métodos e processos científicos destinados ao tratamento do problema racial no Brasil; 2) reeducar os 'brancos' brasileiros, libertando-os de critérios exógenos de comportamento; 3) 'descomplexificar' os negros e mulatos, adestrando-os em estilos superiores de comportamento, de modo que possam tirar vantagem das franquias democráticas, em funcionamento no país (RAMOS, 1957a, p. 163).

Foram criadas instituições que respondessem aos diversos propósitos delineados pelo TEN, como o Comitê Democrático Afro-Brasileiro, voltado para as ações políticas, o Instituto Nacional do Negro, direcionado a ações de "grupoterapia" e apoio psicológico através de valorização 
estética do negro, sob responsabilidade de Guerreiro Ramos. Realizou-se o I Congresso do Negro Brasileiro, no Rio de Janeiro, em 19504. Criou-se o jornal Quilombo ${ }^{5}$ : vida, problemas e aspirações do negro, no qual os trabalhos do TEN foram divulgados, entre 1948 e 1951, com propósitos organizativos da comunidade negra, a que se aspirava intervir.

Nesse momento em que esteve filiado ao TEN, Guerreiro Ramos (1950) a partir de seu diagnóstico da "psicologia diferencial do negro" e do "ressentimento" mantido por estes em relação aos negros de status social superior, bem como em relação aos brancos e mulatos, propôs o que ele denominaria "técnicas sociológicas" para libertar os negros das amarras da brancura e para que assumissem e afirmassem sua negritude. Esta seria uma modalidade de psicologia social a fim de promover uma reconstrução interior e subjetiva do negro. Voltava-se para "adestrar os homens de cor nos estilos de comportamento da classe média e superior" (RAMOS, 1989, p. 23).

Guerreiro Ramos (1950) afirma que o insucesso dos negros resultaria, muitas vezes, de um despreparo cultural. "Este ressentimento é um precipitado emocional da estrutura da sociedade republicana" (RAMOS, 1950, p. 44), afirmava. Após ter sua subjetividade (de)formada pelo regime escravocrata e mantida através de um certo "consenso" reforçado pela violência sobre o negro, a abolição foi incapaz de transformar a mentalidade do mesmo, pois haviam se passado 61 anos do fim do regime escravocrata e nada tinha sido feito de significativo para transformar a "estrutura do caráter do negro".

Neste diagnóstico, o negro ainda preservava um estilo de vida e mentalidade advindos da escravidão. Mas, "se a igualdade jurídica do negro fosse equivalente a uma igualdade econômica e cultural, o seu ressentimento, pelo menos, o social teria sido escasso" (RAMOS, 1950, p. 45). As vivências do negro na sociedade brasileira em meio ao desfecho da abolição da escravidão no Brasil (que não emancipou o negro social,

\footnotetext{
${ }^{4}$ Encontra-se documentado em: NASCIMENTO (1982).

${ }^{5}$ Ver: NASCIMENTO (2003). 
econômica e politicamente) e o preconceito de cor, a experiência cotidiana do negro tornava-lhe retraído e incapaz de transformar sua condição pessoal e social. A grupoterapia visava elevar a autoestima do negro e fornecer-lhe meios de se libertar das tensões emocionais decorrentes do preconceito de cor.

Além da grupoterapia, certa vez, Guerreiro Ramos teve a ideia de que o TEN realizasse um concurso de artes plásticas para elaborar a representação do "Cristo negro". Segundo Nascimento (1980), a repercussão nos comentários dos jornais representantes das "elites tradicionais" e do catolicismo considerou o concurso um atentado à religião oficial. Foi assim que se manifestou o Jornal do Brasil em seu editorial do dia 26 de junho de 1955, considerando injúria ao povo brasileiro e à religião oficial do país o concurso promovido pelo TEN. Segue reprodução de um excerto do editorial, para que o leitor tenha ideia do teor da reação:

Essa exposição que esse anuncia deveria ser proibida como
altamente subversiva. Tal acontecimento, realizado às
vésperas do Congresso Eucarístico, foi preparado adrede de
escândalo e motivo de repulsa. O nosso descontrole moral,
a nossa grande falta de respeito e de bom gosto, o nosso
triste estado de alma, não podem ser dados em espetáculo
aos que nos visitam. Demos aqui nosso brado de alarma.
As autoridades eclesiásticas devem, quanto antes, tomar
providências para impedir a realização desse atentado feito
à Religião e às Artes. O próprio povo brasileiro se sentira
chocado pela afronta feita. (apud NASCIMENTO, 1968,
p. 18-19)

Nascimento (1980) sustenta que os dogmas mantidos pelos estratos dominantes almejam abarcar todos os aspectos existenciais, censurando inclusive a estética e a arte negras como neste episódio. A proposição desse concurso suscitou o velho e tradicional imperativo, a "repetição dos tradicionais estereótipos da 'abnegação' e da 'renúncia' do sofrer calado e sem reclamar”, uma exigência da religião católica 
própria das "qualidades que os brancos em geral esperam dos negros" (NASCIMENTO, 1980, p. 97). A reivindicação de uma representação estética negra de Cristo chegaria ao ponto de causar um atentado à religião, atitude esta que revela a presença marcante do racismo no Brasil.

As iniciativas do TEN de promoção de novos estudos também se deram com a Conferência Nacional do Negro, ocorrida no Rio de Janeiro em 1949, organizada por Abdias Nascimento, Guerreiro Ramos e Edison Carneiro. Dela resultou o I Congresso do Negro Brasileiro, no ano seguinte e na mesma cidade. Com esses eventos de cunho intelectual, mas também abertos à população negra, valoriza-se uma nova perspectiva de estudos sobre o negro, a qual pretendia conciliar caráter científico e patriótico. O TEN visava, segundo Muller (1989), a elaboração de diagnósticos em vista da ascensão social e econômica dos negros através da educação e da cultura. Organizou também a Semana de Estudos do Negro Brasileiro no ano de 1955, no Rio de Janeiro, sede do teatro.

$\mathrm{Na}$ contemporaneidade, uma das reflexões críticas que se faz acerca do discurso desses intelectuais, no caso Guerreiro Ramos e Abdias Nascimento, tende a constatar a "ambivalência e ambiguidade" de suas propostas. Conforme Mauês (1989), haveria "cicatrizes brancas" no discurso desses intelectuais. Os representantes do TEN "caíam na armadilha da visão preconceituosa sobre o negro e por aí acabaram por embranquecê-lo" (MAUÊS, 1989, p. 92). Assim, o TEN dirigia-se não aos afro-brasileiros, mas aos que fossem capazes de deixar de ser negros, pregando uma espécie de puritanismo capaz de livrá-los dos elementos que sustentavam a maculada representação dominante que os brancos erigiram.

Para Muller (1989), a comunidade negra ao ser vista como vítima de um silenciamento social e cultural, os líderes negros interpretaram que deviam exercer uma tutela sobre os afro-descendentes. O TEN atuou no plano "teatral artístico", reiterando o primitivismo espontâneo do negro, na promoção de estudos e encontros que afirmavam seu viés científico e pragmático. Sob o viés do materialismo histórico, a formação de uma 
elite negra e mulata séria converteria a luta de classes num processo, que manteria o equilíbrio e a harmonia social de cooperação, mediado por uma elite negra identificada aos estilos de vida das classes superiores.

É preciso, porém, relativizar essas críticas e lembrar que o TEN e seus protagonistas não mantiveram o mesmo discurso ou as mesmas ideias sobre a questão racial brasileira ao longo dos anos. Na sua trajetória, o TEN apresentava um discurso em transição "entre uma busca declarada dos valores brancos de matriz europeia - marco do pensamento negro nos anos 30 - e uma adesão incondicional ao que pretensamente seriam os valores exclusivamente negros e africanos dos anos 1970" (MAUÊS, 1989, p. 98). Consideremos esta transição de concepções.

A complexidade das relações raciais brasileiras se evidencia no movimento gerado por intelectuais que procuraram compreendê-la desde o final do século XIX, se evidencia na existência de uma vasta literatura especializada sobre o assunto. Literatura que se especializou com a realização do projeto de estudo sobre a temática racial no Brasil proposto pela UNESCO, no início da década de 1950, quando ainda se acreditava que o Brasil era o paraíso racial sistematizado por Gilberto Freyre e difundido pelas nossas elites políticas desde a abolição da escravidão.

\section{GUERREIRO RAMOS E O PROJETO UNESCO}

$\mathrm{Na}$ ocasião do I Congresso do Negro Brasileiro (1950), Guerreiro Ramos apresenta algumas teses ${ }^{6}$ a fim de serem aprovadas e encaminhadas à UNESCO (Organização das Nações Unidas para a Educação, Ciência e Cultura), que na época, discutia a realização de um estudo piloto sobre o tema das relações raciais no Brasil. A UNESCO foi criada em 1946 após o holocausto nazista e a Segunda Guerra Mundial, com a intenção de presidir as ações da ONU por meio de pesquisas, debates e divulgação científica, incorporou à sua agenda a temática do combate ao racismo.

\footnotetext{
${ }^{6}$ Guerreiro Ramos, “A UNESCO e as relações de raça”" (publicado em: NASCIMENTO, 1968), nesse texto encontram-se as propostas de Guerreiro Ramos aprovadas pelo Congresso.
} 
Uma confluência de fatores externos e nacionais elegeu o Brasil como país sede da pesquisa. A existência de um prestígio internacional do país no tocante às relações raciais, advindo de estudos de autores nacionais e estrangeiros, que apontavam o país como um "laboratório de civilização" (Arthur Ramos), uma "democracia étnica" (Gilberto Freyre) e uma "sociedade multirracial de classes" (Donald Pierson) (MAIO, 1997), reforçavam a imagem difundida pelas elites diplomáticas do país no exterior, acerca de uma convivência pacífica entre os diferentes grupos étnicos no Brasil.

Dado o contexto pós-nazista, a crença no caso exemplar brasileiro - cujas antípodas eram os EUA e África do Sul -, a atuação e influência de intelectuais brasileiros na agência (Artur Ramos, Gilberto Freyre, Luiz de Aguiar Costa Pinto, Ruy Galvão), bem como a existência de uma tradição de estudos raciais no Brasil favoreceram a escolha do país (MAIO, 1997).

Maio (1997) demonstra vicissitudes e disputas que estiveram presentes na elaboração do projeto UNESCO no Brasil. Inicialmente, o plano estava voltado para a cidade de Salvador, mas o envolvimento e influência de intelectuais brasileiros e estrangeiros, que mantinham alguma relação com o país, junto ao órgão da $\mathrm{ONU}$, permitiram que o projeto fosse estendido para outras capitais (São Paulo, Rio de Janeiro e Recife). Embora tenha havido abordagens diversas - entre uma perspectiva sociológica de feição universal e iluminista -, preocupada com a mudança social; e, uma perspectiva antropológica, atenta à cultura e ao particular.

O fato é que, segundo Maio (1997), o projeto permitiu um conhecimento mais minucioso da questão no país, o qual deixa de ser visto como modelo exemplar de relações raciais, tendo em vista a confirmação da existência do preconceito de cor, apresentado num quadro teórico plural por meio de análises comparativas dos casos estudados.

No momento em que se disputava a orientação a ser seguida por esses projetos, Guerreiro Ramos (1968) propôs uma agenda de pesquisas de caráter político, que não foi aprovada pela Unesco. No encontro dos 
"experts" foi conferida uma orientação mais acadêmica e científica para o projeto. Costa Pinto se responsabilizou pelo projeto no Rio de Janeiro. Mas, a proposta derrotada do sociólogo baiano, segundo Maio (1997), apresentava-se como alternativa ao que se elaborou, tornando-se uma crítica e contraponto a esses estudos.

Guerreiro Ramos volta-se contra a maioria dos participantes do projeto UNESCO, não isentando nem mesmo a instituição. Escreveu que "tais documentos são frutos de uma visão alienada ou consular do Brasil, de uma visão desde fora do país. Embora redigidos por brasileiros, eles se incluem na tradição dos antigos relatórios para o Reino..., ainda que hoje o reino se metamorfoseie na UNESCO, sediada em Paris..." (RAMOS, 1957a, 155). Em O problema do negro na sociologia brasileira, Guerreiro Ramos tece suas críticas aos autores que direta e indiretamente estiveram envolvidos com o Projeto UNESCO.

Dos cientistas sociais participantes do projeto, apenas Oracy Nogueira não é criticado por Guerreiro Ramos; tampouco Oracy Nogueira é citado nas críticas de Guerreiro Ramos aos estudos de comunidade, estas como as críticas ao Projeto UNESCO, vêm à tona a partir de 1953. Ademais, O Processo da sociologia no Brasil (1953) foi dedicado a Oracy Nogueira, o que indica a existência de uma boa relação entre esses ambos.

\section{ECOS DA NEGRITUDE NO PENSAMENTO DE GUERREIRO RAMOS}

Após a Segunda Guerra Mundial e a eclosão das lutas de libertação colonial pela Ásia, África e América, a negritude surgiu como uma corrente literária no âmbito do colonialismo francês, questionando

\footnotetext{
${ }^{7}$ Reunião realizada em Paris pela UNESCO em que se buscou uma definição interdisciplinar do conceito de raça com vistas a suplantar o significado ideológico construído sobre o termo para orientar as ações da UNESCO. A partir desta iniciativa surge a Primeira Declaração Sobre Raça da UNESCO e as diretrizes para a execução de um projeto científico-político sobre relações raciais, no qual o Brasil foi escolhido como laboratório de pesquisas. Ver: MAIO (1997).
} 
a dominação francesa aos Estados africanos colonizados. Essa literatura, inspiradora dos estudos pós-coloniais, ganhou força com a adesão de intelectuais europeus. Ela simbolizou a luta pela emancipação política dos países africanos do jugo imperialista por meio de movimentos nacionais de libertação colonial. Insurge-se, inicialmente, por meio de uma poesia da negritude como resposta ao racismo colonial e atinge formas distintas de expressão e pensamento, questionando a condição colonial e difundindo-se para outros contextos históricos.

Conforme Munanga, os discursos produzidos pelos escritores da negritude evidenciaram: 1) a busca de uma identidade negra africana; 2) a luta pela emancipação colonial; 3) e o desejo de uma civilização universal que não fosse imposta nem representasse apenas a civilização ocidental, mas o encontro de civilizações particulares. "As análises do pensamento africano moderno põem claramente em evidência todo este esforço, centrado na valorização do passado e na vontade de construir ideologias baseadas na reconquista da identidade, fazendo história como sujeito dela" (MUNANGA, 1986, p. 47). Mas a negritude reiterava a coincidência entre biologia e cultura, e raça e africanidade; essas críticas suscitaram a ideia de pan-africanismo.

Para Zahar (1976), entre Aimé Césaire e Leopold Senghor, teóricos defensores da negritude, houve uma perda de realidade histórica transformadora do movimento, que se converteu em ideologia conservadora ao se desvincular da luta anticolonial. Num primeiro momento, a negritude fez com que o negro (colonizado) referisse a si próprio com altivez, em face do preconceito racial que justificava os arranjos de dominação vigentes. O negro reclamava o conhecimento de sua tradição histórica e a autenticidade de sua cultura, expressava revolta e tomada de consciência por meio da crítica ao falso racionalismo. Manifestava nostalgia de um passado histórico negado pelo colonialismo e revolta-se contra o racismo. Em seguida, porém, a negritude perde sua função crítica com Senghor, ao fabular um passado pré-colonial não histórico, ao fazer apologia à irracionalidade, ao ressentir-se contra a ciência e a técnica, reiterando os estereótipos coloniais como a crença na natureza e ethos sentimental do negro. 
No Brasil houve uma repercussão desse movimento através das atividades promovidas pelo TEN, sobremodo, no que concerne à valorização do negro e à possibilidade de desfazer o estigma criado em relação a ele pelos brancos colonizadores e fundadores do país.

A formação intelectual "antropocêntrica" de Guerreiro Ramos informa teoricamente seus estudos sobre o negro (OLIVEIRA, 1995; BARBOSA, 2006; AZEVEDO, 2006), coaduna-se com o discurso da negritude francófona, às reflexões de Sartre no seu Orpheu Negro. Em vista de objetivos universalistas, este autor manifestou uma contrarreação frente a conceitos discriminatórios, invertendo os polos do discurso e criando o "racismo anti-racista". O "personalismo negro" de Guerreiro Ramos, segundo Barbosa (2006), é caudatário dessas influências intelectuais e se caracteriza por uma "dialética da negritude".

Guerreiro Ramos assume, a partir dos anos 1950, a negritude como perspectiva para pensar a questão racial. Afirmava ele: "sou negro, identifico com o meu corpo em que o meu eu está inserido, atribuo à sua cor suscetibilidade de ser valorizada esteticamente e considero a minha condição como um dos suportes de meu orgulho pessoal [...]" (RAMOS, 1957a, p. 156). Não assumia o supremacismo inicial do branco, como Sartre. A "luta humanista passaria, inevitavelmente, pela assunção dialética de sua prerrogativa circunstancial como negro, tido como o único caminho para que o "homem de cor" pudesse se elevar ao plano da pessoa" (BARBOSA, 2006, p. 218). Para o sociólogo baiano, as pessoas de "pele escura" poderiam suspender a ideologia da brancura e, assim, objetivamente obter a compreensão humanística de sua negritude e da luta negra.

Para Guerreiro Ramos (1957a) os predicados indefinibilidade e dinamismo da pessoa humana se estendem ao negro, não sendo, pois, um objeto de estudo, tal como era tratado pelos estudos etnológicos e sociológicos de seu tempo, que essencializavam o negro. Esses estudos,

\footnotetext{
${ }^{8}$ Sartre destacou-se por ter influenciado alguns autores denominados de "pós-colonialistas", isto é, originados de países colonizados que estudaram nas nações do centro do capitalismo e inauguradores de uma postura teórica não eurocêntrica.
} 
o autor se dispôs a rever criticamente. Nesses termos, a classificação e definição do negro diz respeito, antes à sua desumanização por parte de uma identidade adjudicada a ele pelo branco, do que propriamente a um modo de conhecer as condições de vida que essa parcela da população enfrentava, e à maneira de melhorá-las, incorporando-a à nação que se acreditava possível construir.

Com isso, Guerreiro Ramos procurou denunciar a remanescência de padrões estéticos europeus, manifesta numa atitude alienada e subserviente desses estudos, que se fundamentam, segundo ele, nos conceitos produzidos pelos colonizadores em seus contextos de origem, sem problematizá-los à luz da realidade nacional. Nota-se uma postura teórica pós-colonial ${ }^{9}$ de Guerreiro Ramos, a partir da década de 1950, a qual vai culminar em seu livro $A$ redução sociológica.

Guerreiro Ramos afirma ainda que os conceitos usados pelos sociólogos de seu tempo, raça, raça-classe, homem marginal, aculturação, estrutura social, mudança social, categoria ecológica de área, estrutura e função supõem uma "concepção quietista da sociedade e, assim, contribuem para a ocultação da terapêutica decisiva dos problemas humanos em países subdesenvolvidos" (RAMOS, 1957a, p. 125).

Esta crítica surge após o autor estar vinculado ao Iseb, depois de ter rompido relações com Costa Pinto e iniciado um debate com Florestan Fernandes, o qual foi muito proveitoso para a elaboração de uma visão global da sociedade brasileira por parte deste último. Com isso, é possível afirmar que, em vez do que ficou consagrado por Ianni (2004), a elaboração de uma "sociologia crítica e militante" no Brasil, entre 19451955, está mais próxima das formulações de Guerreiro Ramos do que das preocupações científicas de Florestan Fernandes, naquele momento.

A crítica de Guerreiro Ramos, em relação ao conceito de aculturação, aproxima-se da concepção de Frantz Fanon, segundo a qual havia uma dominação cultural que atingia a psique dos colonizados indispondo eles de si mesmos e convertendo-os em objeto de dominação. A aculturação "supõe ainda uma espécie de defesa da brancura de nossa herança cultural,

\footnotetext{
${ }^{9}$ Sobre esta interpretação do autor, ver: MAIA (2009, 2012).
} 
supõe o conceito da superioridade intrínseca do padrão de estética social de origem europeia" (RAMOS, 1957a, p. 155). Conforme o sociólogo baiano, havia um significado imperialista no conceito, pois pressupõe que uma cultura "vale mais" do que outra e abstrai a cultura de demais fatores influentes no processo de contato social.

Frantz Fanon parece ter inspirado Guerreiro Ramos (1957a, 1966) nas reflexões sobre a condição do negro no Brasil, com suas análises em torno da psique dos colonizados. Fanon criticou a perspectiva universalista do marxismo, que reconhece apenas as assimetrias baseadas na questão das classes sociais, ignorando o ponto de vista do racismo e da alteridade socialmente construída. Conforme ele, o colonialismo francês anulou a subjetividade dos colonizados, transformou o negro em objeto, classificou o negro por meio de predicados desprezíveis. Enquanto o branco colonizador exaltava-se a si mesmo. Para o negro, o branco não seria apenas o outro, mas, sobretudo, o seu senhor imaginário e efetivo. Chegara o momento de romper com esta situação.

Fanon, segundo Zahar (1976), insurgiu-se contra o colonialismo postulando a ruptura do consenso ou da alienação a que estavam submetidos os colonizados através de mecanismos e processos de consciência criados pelo sistema colonial francês. $\mathrm{O}$ fator raça e sua ideologia correspondente eram essenciais para a manutenção da ordem baseada na violência. Além disso, a pretensa superioridade do branco europeu era reconhecida pelos oprimidos através de um processo de alienação.

Segundo Fanon era preciso romper com a alienação psicológica e voltar-se contra o colonizador pelos meios possíveis, ainda que violentos, pois o recurso da força era recíproco. A violência anticolonial seria uma práxis totalizante que liberta o colonizado de suas alienações. Para Frantz Fanon, segundo Zahar (1976), a questão das classes sociais e a consciência política de classe eram ofuscadas pelo racismo e a imposição de uma identidade essencialista aos negros, que consentiam com a imagem de si elaborada pelo colonizador.

Já Guerreiro Ramos (1957), inculcado pelos ideais de uma intelligentsia nacional, minorava a importância das classes sociais. Acentuava a nação 
como lugar privilegiado, no qual os diferentes interesses dos grupos sociais poderiam ser equacionados. $\mathrm{Na}$ visão dele, a solidariedade nacional transcendia a de classe, a solidariedade dos trabalhadores, acabando mesmo por incorporá-la ao projeto de emancipação nacional.

Muito embora, Guerreiro Ramos (1957) tenha elaborado uma crítica à estética social e à patologia do branco, aproximando-se às ideias de Frantz Fanon, o sociólogo baiano, em alusão ao seu contexto histórico, distingue-se das ideias do escritor e ensaísta martinicano, o qual defendia e fundamentava a violência contra os brancos.

Guerreiro Ramos postulava a necessidade de reeducação das partes envolvidas nos conflitos inter-raciais: o branco, o mulato e o negro. Com isso pretendia despertar nestes grupos étnicos o sentido democrático da convivência e a unidade como povo brasileiro. Para este sujeito-conceito, recente na história política brasileira, mas cindido por cortes raciais e ideológicos, a tarefa maior era, segundo o sociólogo, a de fundar uma nação autêntica através do desenvolvimento econômico independente com distribuição dos recursos e por meio da democratização das instituições políticas brasileiras. Este último aspecto despertou a atenção de Guerreiro Ramos após sua saída do Iseb até as vésperas da ruptura política conservadora de 1964.

\section{O NEGRO SOB A NECESSIDADE DE ORGANIZAÇÃO DA NAÇÃO}

$\mathrm{Na}$ condição de membro da Assessoria do segundo governo de Getúlio Vargas, em 1952, Guerreiro Ramos participa do Grupo de Itatiaia, que no ano seguinte, deu origem ao IBESP (Instituto Brasileiro de Economia Sociologia e Política), órgão que publicou o periódico Cadernos do Nosso Tempo (1953-1956).

A formação de uma intelligentsia organizada por seus próprios meios confere a tônica da intenção de intelectuais com visões teóricas e políticas distintas, que elaboravam conhecimentos da realidade brasileira. 
Os diagnósticos se destinavam a facultar intervenção não apenas no debate político da época, mas principalmente na realidade brasileira de seu tempo, em vista do processo de industrialização com bases nacionais. O desenvolvimento de uma ideologia nacionalista, de um pensamento genuinamente brasileiro era visto, por excelência, como o meio que facultaria a atuação desses intelectuais, cujo objetivo voltava-se para um trabalho de síntese dos interesses dos diversos grupos sociais e de esclarecimento teórico dos dilemas enfrentados pelo país (SCHWARTZMAN, 1979, BARIANI, 2008).

O nacionalismo para Guerreiro Ramos era circunstancial e oportunista. Um meio de aglutinação das forças políticas progressistas do período, de organização de uma vontade política para viabilizar a autonomização da economia brasileira. Implicava aproximação com os "países livres", "não alinhados" nem aos EUA nem a URSS, ruptura com o subdesenvolvimento e o imperialismo, promoção da democratização das instituições políticas brasileiras para que se adequassem ao primeiro código eleitoral de 1945, que ampliara a participação popular sem mudar as instituições e romper com as práticas políticas oligárquicas e populistas vigentes.

A presença e o envolvimento de Guerreiro Ramos nos debates promovidos pelo Grupo de Itatiaia e pelo IBESP ressoaram nos estudos do autor sobre o negro, não obstante, sua produção intelectual já não estava mais diretamente vinculada à rotina de uma instituição - como quando em sua participação profissional no DASP -, e sim, mais próxima ao livre exercício da reflexão, em vista de propósitos políticos intervencionistas. O diferencial reside no fato de não haver mais uma relação direta de suas publicações com suas atividades profissionais e tampouco vinculada a uma militância de caráter pontual, como no TEN.

$\mathrm{O}$ autor havia ascendido nos meandros do poder na antiga capital federal, ocupando o cargo de assessor do Presidente da República, bem como se tornado professor e um dos fundadores da Escola Brasileira de Administração da Fundação Getúlio Vargas (EBAD/FGV). Participava de uma intelligentsia preocupada em elaborar um projeto nacional de 
desenvolvimento, no qual as questões pontuais cederam espaço para a busca de uma interpretação abrangente, uma teoria geral do Brasil ${ }^{10}$.

Para Guerreiro Ramos, naquele momento, antes de 1956, quando a economia brasileira não havia sido tão internacionalizada e dominada pelo capital estrangeiro, a antropologia e demais ciências sociais deveriam se articular com o processo de desenvolvimento econômico da sociedade brasileira daquele contexto, a fim de "induzir" da realidade histórica do país critérios para uma práxis transformadora.

Apenas uma visão global e abrangente daria suporte a um projeto de nação, à luz do qual, os problemas postos pela antropologia mostrar-seiam passageiros. "Nossos problemas culturais, no sentido antropológico, são particulares e dependentes da fase de desenvolvimento econômico do Brasil. A mudança faseológica de nossa estrutura econômica automaticamente solucionará tais problemas" (RAMOS, 1957a, p. 127). Raciocinava o autor, em defesa do desenvolvimento econômico nacional independente, sob uma perspectiva evolucionista do progresso, neste momento.

A revisão dos estudos sobre o negro, proposta por Guerreiro Ramos (1953), denuncia abordagens que conceberiam o negro como espetáculo, um ser estático, imutável e dotado de uma essência "negra" (pejorativa), ou de estudos históricos puramente descritivos e explicativos. Além dos autores envolvidos no projeto UNESCO, as críticas de Guerreiro Ramos voltavam-se também contra os estudos realizados sobre o negro pelos autores Nina Rodrigues, Arthur Ramos, Gilberto Freyre, Gabriel Soares de Souza, Saint Hilaire, Hans Staden, Alfred Métraux, Donald Pierson, Charles Wagley, Herskovits, Emílio Willems.

O distanciamento da "realidade nacional" se refere ao fato de que, em vez de manifestar um compromisso com as questões históricas a ser

\footnotetext{
${ }^{10}$ O problema do negro na sociologia brasileira foi publicado no segundo número dos Cadernos do Nosso Tempo, constituindo-se como mais uma das contribuições teóricas que esses intelectuais pretendiam oferecer ao debate político nacional. Daí em diante o autor passa a defender, cada vez mais, uma visão do todo ou do conjunto da sociedade brasileira, ampliando seu leque temático-investigativo à luz de uma intervenção política que se tornasse viável.
} 
resolvidas pelo processo de abolição do regime escravocrata no Brasil, alguns desses autores concebiam o negro como objeto de curiosidade, como "material etnográfico" e algo "pitoresco". Com essa posição intelectual política, eles contribuíam para o desvio da atenção das nossas "elites" no sentido programático suscitado pelo processo de abolição da escravidão por intelectuais como Joaquim Nabuco.

Ao passo que outros autores do pensamento brasileiro, não obstante os limites impostos à suas teorias, mediante perspectivas correntes e hegemônicas de seu tempo, são apresentados como pertencentes a uma corrente crítica que Guerreiro Ramos (1957a) reclama para si sob algumas reservas. Sylvio Romero, Euclides da Cunha, Alberto Torres e Oliveira Viana, segundo ele, tiveram uma atitude "crítico assimilativa", de desconfiança em relação ao uso de conceitos das ciências sociais estrangeiras, alheios à realidade nacional. Além disso, esses autores viram o negro como um elemento da população, um ser dinâmico, que se transformaria historicamente e seria, sobretudo, brasileiro. Tratar-se-iam de iniciativas teóricas pioneiras, que confluíam para a sociologia crítica e de contraponto, reivindicada por Guerreiro Ramos.

Além dessas contribuições teóricas, ele também se diz inspirado nos trabalhos com intenções "pragmáticas", de libertação dos negros, como o africano Chico Reis, que organizou um movimento para alforriar escravos. Rememora as insurreições de escravos muçulmanos na Bahia, organização de quilombos e a "república dos Palmares”, Luiz Gama e José do Patrocínio, que se sobressaíram na campanha abolicionista; bem como associações e clubes negros, as Frentes Negras de São Paulo e da Bahia e o TEN. Os intelectuais Joaquim Nabuco e Álvaro Bomilcar eram também admirados por Guerreiro Ramos.

As soluções dos problemas existenciais do "negro vida" são transpostas para o âmbito da nação a fim de efetivar o discurso de uma democracia racial autêntica. Durante a Semana de Estudos do Negro Brasileiro, realizada pelo Teatro Experimental do Negro (TEN) no ano de 1955, foi declarada uma carta de princípios, redigida por Guerreiro Ramos, na qual se sugere: 
É desejável que o Governo brasileiro apoie os grupos e as instituições nacionais que, pelos seus requisitos de idoneidade científica, intelectual e moral, possam contribuir para a preservação das sadias tradições de democracia racial no Brasil, bem como para levar o nosso país a poder participar da liderança das forças internacionais interessadas na liquidação do colonialismo (RAMOS, 1957a, p. 202).

Um dos meios privilegiados pela análise de Guerreiro Ramos (1957, 1966), consequentes às suas intenções políticas em favor de uma integração democrática efetiva dos "elementos de cor" na sociedade brasileira, refere-se à "suspensão da brancura" por meio da criação de uma estética social autêntica ${ }^{11}$ em relação ao contexto brasileiro de relações interétnicas. A autenticidade no âmbito das representações estéticas por si só não abolia o problema da alienação, uma vez que isso demandava ações de caráter econômico e político nas relações do Brasil com os países do centro capitalista.

O desenvolvimento nacional autônomo perpassa a esfera da cultura e, assim, a existência de uma estética social autêntica confluiria aos propósitos de autonomia nacional, em virtude de uma não subserviência a padrões e critérios estrangeiros na organização da nação, e tampouco na configuração das relações interétnicas.

$\mathrm{Na}$ atitude de quem associa a beleza negra ao meramente popular, folclórico, ingênuo ou exótico, há um preconceito larvar, uma inconsciente recusa de aceitá-la liberalmente. Eis porque é digna de repulsa toda atitude que, sob a forma de folclore, antropologia ou etnologia, reduz o saberes

\footnotetext{
${ }^{11}$ No jargão existencialista, autenticidade diz respeito à assunção da própria particularidade, de modo consciente, julgando-se e afirmando-se na história, em detrimento de ideias atribuídas por outrem, alheias. (ZAHAR, 1976). A autenticidade, para o negro, significa "idoneidade consigo próprio, adesão e lealdade ao repertório de suas contingências existenciais imediatas e específicas. E na medida em que ele se exprima de modo autêntico, as versões oficiais a seu respeito se desmascaram e se revelam nos seus intuitos mistificadores, deliberados ou equivocados. (RAMOS, 1966, p. 135).
} 
negros ao plano do ingênuo, ou do magístico. Num país de mestiços como o nosso, aceitar tal visão constitui um sistema de auto-desprezo ou de inconsciente subserviência aos padrões estéticos europeus (RAMOS, 1966, p. 131).

Essa normatividade postulada por Guerreiro Ramos (1957a) resulta de seu diagnostico acerca da "brancura". A atitude imperialista, segundo a qual brancos e negros são opostos e identificados por atributos enobrecedores e pejorativos respectivamente, seria corroborada no Brasil pelas "elites", pelos intelectuais ${ }^{12}$ e pela "massa". Aproximando-se das análises de Frantz Fanon, o autor diagnostica os diferentes significados criados historicamente em torno da cor branca e da cor negra, sempre tendentes a polarizá-los em termos de bom e mau, bem e mal, e, belo e feio. "Se se reduzisse a axiologia do mundo ocidental a uma escala cromática, a cor negra representaria o polo negativo", explica o autor (RAMOS, 1966, p. 128).

Muito embora esta representação fosse uma identificação criada no e pelo ocidente, durante o processo de subjugação dos demais povos, tratava-se de um olhar e de um princípio que afeta a todos. Assim, tanto brancos como mulatos e negros sofrem de obnubilações no que concerne à cor negra e seu significado humanístico. A "brancura" é vista como um obstáculo para a organização da nação na medida em que impedia a integração e capilaridade social ${ }^{13}$ dos diferentes grupos étnicos, e a participação do negro nos benefícios do desenvolvimento nacional.

\footnotetext{
${ }^{12}$ Em crítica a Vinícius de Moraes, Mario de Andrade, Jorge de Lima, Nícolas Guillén e a "legião de seus imitadores", Guerreiro Ramos diz que se surpreende com algumas páginas produzidas por estes, nas quais são reforçados esteriótipos como: 'Branca para casar, negra para cozinhar, mulata para fornicar!'. 'Labora pela ocultação da negrura toda esta pátina de associações pejorativas e de equívocos sinceros que vestem nosso espírito e que precisam ser purgados mediante a reiteração, em termos egrégios, dos valores negros [...]” (RAMOS, 1957a, p. 196).

${ }^{13}$ Conceitos como os de elite, massa e capilaridade social revelam o uso de categorias de Vilfredo Pareto. Esta última relaciona-se ao processo de circulação das elites no poder político e tem como pressuposto fundamental a ascensão de determinados grupos sociais, como indica Guerreiro Ramos (1957a).
} 
Dificultava a tomada de consciência nacional por parte dos envolvidos no conflito racial. Impedia que os diferentes contingentes étnicos da população brasileira de identificassem como povo brasileiro.

Guerreiro Ramos (1957a) aponta ainda que a "patologia da brancura" afeta os pensadores sociais dos estados do nordeste, onde havia maior contingente de pessoas de pele negra. A manifestação racista de alguns intelectuais representava a negação de seu contexto. Ao reproduzirem a "ideologia da brancura", esses intelectuais sofriam, segundo ele, de uma "patologia", designada como paranóia.

As minorias 'brancas' destes estados, de longa data, têm mostrado tendências para não se identificar com a circunstância étnica imediata. Sentem-na como algo inferiorizante e por isso, lançam mão, tanto quanto podem, de recursos que camuflem as suas origens raciais. Estes recursos são inumeráveis, desde os mais sutis até os mais ostensivos (RAMOS, 1957a, p. 181).

Não se identificando com o seu contexto imediato, com as condições étnicas do país, o protesto racial dos brancos - por vezes elaborado em nome da ciência e de uma sociologia "alienada" dos problemas nacionais -, reivindicava interesses que iam contra a nação, pessoa coletiva que estava por se formar a partir da atuação política do povo. A questão racial passa, assim, a ser equacionada no projeto de nação independente e autêntica defendido pelo autor.

\section{CONSIDERAÇÕES FINAIS}

As questões postas por Guerreiro Ramos em relação à temática do negro acompanharam a evolução de seu pensamento e as instituições que esteve filiado nas décadas de 1940 e 1950 do século passado (DASP, TEN, IBESP, ISEB). Mantiveram uma preocupação fundamental de educar 
o negro para que ascendesse socialmente e participasse das decisões políticas e administrativas, que constroem os rumos da sociedade brasileira.

A princípio, o autor considerava que o preconceito de cor era mais um sintoma das desigualdades na apropriação de oportunidades educacionais, culturais e econômicas gestadas pelo regime de classes sociais do que um problema racial em si mesmo. Mas, posteriormente, Guerreiro Ramos admite a existência do preconceito racial, designado por ele como se tratando de preconceito de cor. Os estudos sobre o negro o conduziram não apenas a revisitar a literatura antropológica e sociológica produzida no Brasil sobre o tema, como também a pensar a nação brasileira.

Ao diagnosticar o problema do negro, Guerreiro Ramos descobre que a nação brasileira estava ainda por ser organizada, alimentando a possibilidade de um capitalismo autônomo no Brasil e depositando esse intento no saber sociológico. A resolução da questão racial deveria perpassar as partes envolvidas no conflito: brancos, mulatos e negros. Nestes termos, Guerreiro Ramos esperançava que o Brasil se efetivasse numa democracia racial autêntica e servisse de exemplo contra o colonialismo para as nações do mundo. A questão racial diz respeito, assim, à questão da sociologia e como esta devia se posicionar mediante a questão nacional.

Todavia, ao pressupor a corrente crença, ainda em voga no seu tempo, que desqualificava o negro como sendo incapaz de ter consciência de suas necessidades históricas, de se organizar e mesmo de ocupar posições de mando, Guerreiro Ramos propõe uma consciência sociológica restauradora da verdade. Manteria sua intervenção intelectual e política certas "cicatrizes brancas"?

Ao que parece, após a realização do projeto Unesco no Brasil, Guerreiro Ramos $(1953,1957 a, 1966)$ radicaliza sua posição em relação ao tema, denunciando o caráter dos estudos sociológicos que, tal como uma corrente do pensamento social representada por Nina Rodrigues, admitiam uma visão estática, exótica, demasiado histórico descritiva e explicativa, que ele denomina "alienada", por não suscitar uma atitude crítica em relação às ciências sociais estrangeiras e tampouco em relação aos problemas nacionais. 
Ao denunciar a "ideologia da brancura”, Guerreiro Ramos (1957a) assume uma postura segundo a qual a assunção da negritude não resolveria por si só os "problemas do negro", pois estes teriam de ser resolvidos no âmbito nacional. O equacionamento da questão racial demandaria isto sim, a assunção da nacionalidade brasileira por todos os grupos étnicos envolvidos no conflito (o "povo brasileiro"), com o reconhecimento de uma circunstância histórica miscigenada, particular, da qual se poderia derivar um projeto de nação.

Assim, Guerreiro Ramos (1957a) parece relativizar as pretensões anteriores que tendiam a reiterar o preconceito contra o negro, supondo debilidades, criticando costumes e propondo seu embranquecimento para vislumbrar a contribuição que poderia ser dada à sociedade nacional por este grupo. A assunção da negritude para resolução das questões históricas legadas pela escravidão como o preconceito de cor e a desigualdade social e econômica, efetivar-se-iam através de uma intervenção protagonizada pela sociologia: por uma intelligentsia e sua ação no âmbito educacional e cultural. A solução da questão racial com base na negritude transformaria o Brasil numa verdadeira democracia racial com propósito de servir de modelo para as demais nações colonizadas.

Já a epígrafe deste artigo deve ser compreendida no âmbito da derrota sofrida pelos setores ideologicamente progressistas daqueles idos. Nacionalistas, democratas e socialistas, com o Golpe civil-militar de 1964, amargaram de vez a bancarrota de seus projetos de construir uma economia independente, uma nação autêntica, autônoma e democrática nos planos político, social e econômico. A "geração perdida", a qual se devotou a pensar o Brasil 24 horas por dia e a enfrentar de camisa em manga os problemas nacionais, percebeu rapidamente que o regime ditatorial aprofundara o privatismo e a internacionalização da economia brasileira, mudara conservadoramente a sociedade, sob os custos do agravamento de problemas estruturais, inclusive o "racismo brasileiro". 


\section{BIBLIOGRAFIA}

AZEVEDO, Ariston. A sociologia antropocêntrica de Alberto Guerreiro Ramos. Tese (Doutorado em sociologia política). Florianópolis, UFSC, 2006.

BARBOSA, Muryatan Satana. Guerreiro Ramos: O personalismo negro. Tempo Social, revista de sociologia da USP, v. 18, n. 2.

BARIANI Jr., Edson. Guerreiro Ramos e a redenção sociológica: Capitalismo e sociologia no Brasil. Tese (Doutorado em sociologia). Araraquara: UNESP FCLAR, 2008.

GUIMARAES, Antonio Sérgio Alfredo; MACEDO, Márcio. Diário Trabalhista e democracia racial negra dos anos 1940. Dados. 2008, vol. 51, n. 1, p. 143182.

GUIMARAES, Antônio Sérgio Alfredo. Preconceito de cor e racismo no Brasil. Rev. Antropol. 2004, vol.47, n. 1, p. 943.

IANNI, Octávio. Florestan Fernandes e a formação da sociologia brasileira. In:__. Florestan Fernandes: sociologia crítica e militante. São Paulo: Expressão Popular, 2004. p. 15-76.

MAIO, Marcos Chor. A bistória do Projeto Unesco. Estudos raciais e ciências sociais no Brasil. Tese (Doutorado em Ciência Política). IUPERJ: Rio de Janeiro, 1997. p. 345.

MAIA, João Marcelo E. Reputações à brasileira: o caso de Guerreiro Ramos. Sociologia\& Antropologia |v. 02.04: 265 -291, 2012.

. Pensamento brasileiro e teoria social. Notas para uma agenda de pesquisa. RBCS Vol. 24 n. 71 outubro/2009.

MAUÊS, Maria Angélica da Matta. Entre o branquemento e a negritude. O TEN e o debate da questão racial. In: MULLER, Ricardo Gaspar (Org.) Dionysos. Brasília: Imprensa Nacional/Minc, 1989. 
MULLER, Ricardo Gaspar (Org.). Identidade e cidadania: O teatro experimental do negro. In:___. (org.) Dionysos. Brasília: Imprensa Nacional/Minc, 1989.

MUNANGA, Kabengele. Negritude. Usos e sentidos. São Paulo: Ática, 1986.

NASCIMENTO, Abdias do. Teatro experimental do negro: trajetória e reflexões. Estud. av. 2004, vol. 18, n. 50.

- Quilombo: Edição em fac-símile do jornal dirigido por Abdias do Nascimento. São Paulo: Editora 34, 2003.

- Quilombismo. Petrópolis: Editora Vozes, 1980.

. Cristo negro: atentado à religião católica. In: - Quilombismo.

Petrópolis: editora Vozes, 1980.

. O negro revoltado. Rio de Janeiro: Edições GRD, 1968.

. Et al. Relações de raça no Brasil. Rio de Janeiro: Edições Quilombo, 1950.

OLIVEIRA, Lúcia Lippi. A sociologia do Guerreiro. Rio de Janeiro: UFRJ, 1995.

RAMOS, Alberto Guerreiro; GARCIA, Everaldo da Silva. Notícia sobre as pesquisas e os estudos sociológicos no Brasil (1940-1949). Rio de Janeiro: Conselho de Imigração e Colonização, 1949.

RAMOS, Alberto Guerreiro. Uma experiência de grupoterapia. In: NASCIMENTO, Abdias et al (org.) Relações de raça no Brasil. Rio de Janeiro: Edições Quilombo, 1950. p. 2126.

RAMOS, Alberto Guerreiro. O negro no Brasil e um exame de consciência. In: NASCIMENTO, Abdias et al (org.) Relações de raça no Brasil. Rio de Janeiro: Edições Quilombo, 1950. p. 33-46. 
RAMOS, Alberto Guerreiro. O museu como sucedâneo da violência. In: NASCIMENTO, Abdias et al (org.) Relações de raça no Brasil. Rio de Janeiro: Edições Quilombo, 1950. p. 47-50.

RAMOS, Alberto. Guerreiro. O processo da sociologia no Brasil. Esquema de uma história das ideias. Rio de Janeiro, 1953.

. Um herói da negritude [1952]. In: NASCIMENTO, Abdias (org.) Teatro experimental do negro. Testemunhos. Rio de Janeiro: Edições GRD, 1966. p. 104106.

O negro desde dentro [1955]. In: NASCIMENTO, Abdias (org.) Teatro experimental do negro. Testemunhos. Rio de Janeiro: Edições GRD, 1966. p. 128135.

. A UNESCO e as relações de raça. In: NASCIMENTO, Abdias. O negro revoltado. Rio de Janeiro: Edições GRD, 1968. p. 153-159.

- Introdução crítica à sociologia brasileira. Rio de Janeiro: Editorial Andes Ltda, 1957.

- A redução sociológica. Introdução ao estudo da razão sociológica. 2 ed. Rio de Janeiro: Edições Tempo Brasileiro Ltda, 1965.

SCHWARTZMAN, Simon. Simpósio Guerreiro Ramos: Resgatando uma obra. In: Revista de Administração Pública, RJ, 17 (2), 1983, p. 3034.

SCHWARTZMAN, Simon (sel. e introd.). O pensamento nacionalista e os “Cadernos de Nosso Tempo". Brasília: UNB/Câmara dos Deputados, 1979. (Biblioteca do pensamento político republicano).

TOLEDO, Caio Navarro. Iseb: Fábrica de ideologias. 2ed. São Paulo: Ática, 1982.

ZAHAR, Renate. Colonialismo e alienação: Contribuição para a teoria política de Frantz Fanon. Lisboa: Terceiro mundo e revolução, 1976. 
